\title{
Formation of the Medicine Faculty Students Physical Health Using Latin Catch Phrases
}

\author{
Zhuravleva Yu.S. \\ Department of physical education and sports \\ RUDN University \\ Moscow, Russia \\ Kubenina73@mail.ru
}

\author{
Borodina M.A. \\ Department of foreign languages, \\ RUDN University \\ Moscow, Russia \\ Borodina@ mail.ru
}

\author{
Pastukhov I.S. \\ Department of physical education and sports \\ RUDN University \\ Moscow, Russia \\ Ivansergeev9200@mail.ru
}

\begin{abstract}
Physical development and behaviour are of no small importance in the profession of a doctor, since he must be strong, healthy, and have significant sanitary and hygienic awareness. The doctor is obligated to monitor his posture and gait, quickly react, overcome possible difficulties, and strive to develop a strict mode of his both professional and personal activities.

The psychological and pedagogical aspect of physical education is one of the fundamental factors in the formation of the future specialist personality, especially a physician, who must not only take care of his patient health, but also of his own one.

Therefore, every teacher who works with students of the medical faculty is doubly obligated to educate and develop physical culture in students.
\end{abstract}

\section{Keywords_physical training; physical health; students.}

\section{INTRODUCTION}

The formation of the moral and physical values of the student is an integral task in the education of the younger generation [3]. For students it is crucial to be aware of their future occupation significance, thus that awareness can become a huge factor in the motivation for learning, which in return determines the quality of specialist training and the formation of students' "moral-value self-awareness". The development process of a future specialist is impossible without the development of his mental and healthy lifestyle.

\section{LITERATURE REVIEW}

It is very important for physical education teachers to pay special attention to these students, since without professional knowledge in the field of sports such as: preventing injuries, various diseases and observing personal hygiene during physical exercises, it is impossible to fully master your own future professional activities [1,2,6,7].

In regards to Latin teachers who regularly act as the curator of a student group (from lat. Curator, oris $\mathrm{m}$ - one who cares, treats, supervises, educates; a trustee), it should be noted that in their work they can turn to help through history, by the expressions of wise philosophers who left their heritage in the monuments of ancient literature.

\section{RESULTS}

By studying various reference books and dictionaries with winged Latin expressions that characterize a person's physical health in one way or another, the latter can be divided into several thematic groups depending on the semantic context inherent in the phrase.

The first group consists of expressions in which a person's health is dependent on his nutrition and hygiene, in other words, a person's proper nutrition helps to maintain health or improve it. In particular, Fructus cape cum pane, si vis vivere sane - "Eat fruit and bread if you want to be healthy." Literally, the first part is translated as "absorb fruits with bread", in other words, bread is considered as the main food, and the word "fructus, us m" is translated from Latin as "fruit", which includes not only fruits as such, but also vegetables. As a result, this expression carries a very clear meaning that, with the correct consumption of vegetables and fruits with bread, a person will always be full, and therefore healthy.

Natura homo mundum et elegans animal est - "Man by nature is a clean and tidy creature." From the Latin language, "mundus, a, um" means clean, neat, elegant, "elegans, ntis" legible, refined, skilful, sophisticated, beautiful. Based on the meanings of Latin adjectives, the meaning of this saying belonging to Seneca ("Moral Letters to Lucius, 92, 12") is much broader. Here we have a complete description of the qualities that a person should possess and thereby be different from the animal: the purity of the soul and body, the purity of thoughts and actions. At Seneca: "Choosing clean clothes is a worthy example of aspirations, because a person by nature is a clean and tidy creature ... The blessing is not in the thing itself, but in its choice" (per. S. Osherova). The uniform of the medical worker - a clean white coat or a clean blue (or green) 
surgical suit and hat - sets the patient in a positive mood and the physician himself for a pleasant and fruitful work.

The second group of aphorisms shares the meaning of constant work, both physical and mental. Regular and tireless work on oneself can lead to physical and spiritual health. Nulla dies sine linea - "Not a day without a line", therefore, not a day without laziness, albeit a little, but making efforts to achieve your goal, therefore, for a student is nothing more than the formation of a professionally developed personality as a doctor or pharmacist. The source of this phrase is the story of Pliny the Elder about Apelles, the Greek painter of the 4th century. BC. (Natural History, XXXV, 36, 12). This artist had one distinctive feature: no matter how busy he was, he would not miss a single day without practicing his art, drawing at least one line. It served as the basis for the saying "nulla dies sine linea". This expression can serve as an excellent motto not only for artists and writers, but also for doctors who must develop and improve every day in medicine, so as not to become useless to other people.

Studiaadulescentiamalunt - "Classes Nourish Young Men." In fact, this statement of Cicero is much wider than his translation. Having examined the meanings of the words included in the expression (the verb alo, alui, alitum, ere means to nourish, nurture, develop and strengthen, heal and heal; stadium, in is effort and diligence, aspiration, occupation and profession, study, science), we get that this is not just about occupations, but about a profession, about science or the branch of knowledge that a person devotes himself to and the most amazing thing is that a true desire and zeal in his profession can heal a person, that is, reveal to him the truth of knowledge . Cicero, in his defense of the poet Archieus, says [7]: "Classes nourish young men, bring delight to the elderly, decorate in happiness, serve as a refuge and comfort in misfortune."

Ad cogitandum et agendum homo natusest - "Man was born for thought and action." To engage and reason - these are the basic tenets of human existence. Corpora juvenumlaborefirmantur - "The bodies of the young are strengthened by labor." The expression is based on the words of Cicero ("Tusculan Conversations, II, 15, 36"): "The habit of work also facilitates the transfer of pain. That's why the organizers of the Greek states tried to temper the bodies of young men with labour" (per. M. Gasparova). From the Latin language, the verb firmo, avi, atum, are means to make strong, temper, strengthen. Therefore, engaged in a specific business, working on a goal, a person is distracted from his ailments, troubles, moving away from them, thereby tempering his body, becoming stronger and as a result asserts itself [5].

The third group of aphorisms is aimed at the physiological health of a person, the formation of independent decision-making skills in order to maintain and strengthen one's health, the development of habits, and then the requirements for observing personal hygiene rules, and for observing elementary rules for keeping one's body clean.

Hygienaamicavaletudinisest - "Hygiene is the friend of health". Often the teacher is faced with the problem of unpleasant stink from students, due to their uncleanliness. In this case, this aphorism can help, because when students learn that the word "hygiene" came from the name of the Greek goddess of health, Hygiea, the daughter of the healing god Asclepius, who was portrayed as a young woman feeding a snake from the bowl. It became the emblem of medicine, and begin to understand that a doctor who carries health to a person is inseparable from cleanliness, i.e. hygiene, young medical students begin to think about the purity of their bodies [4]. In Latin, the word "snake" is translated as vipera, ae $\mathrm{f}$ from vivus + pario, which means "living" and "give birth, produce." This meaning symbolizes the omen of fate, life and death.

Menssana in corpore sanobonum magnum est - "In a healthy body, a healthy mind is a great blessing." In other words, if a person is not burdened by illness, and he is far from pain and ailments, then his consciousness will only work to enrich his spiritual beginning, therefore, constant work is necessary to maintain and strengthen his health.

The fourth group of aphorisms represents hard work and patience in order to achieve victory over oneself. Citius, altius, fortius! - "Faster, higher, stronger!", The famous motto of the Olympic Games and the inscription on the Olympic medals. The games got their name in honour of Olympia - a small town in southern Greece, where the temple of Olympian Zeus was located with its famous statue of the Athenian master Phidias. It was considered in ancient times one of the seven wonders of the world. At the temple there was also a place for competitions dedicated to Zeus. The games were held every four years, during the summer solstice, starting from $776 \mathrm{BC}$. throughout Greece for these 5 days a sacred truce was declared. They competed in running, long jumps, discus and spear throwing, wrestling, and later on horseback riding, chariot riding and poetic mastery. The winners were awarded with olive wreaths and revered as the favourites of Zeus: they arranged celebrations in their honour, erected statues, composed laudatory odes. The Olympic Games were cancelled by the Roman Emperor Theodosius in 394 BC, during which the reign of Christianity was finally established in the empire. As world sports competitions they have been held since 1886, for the first time in Athens. This aphorism helps to comprehend the way to achieve your goal: not just become a doctor but a professional, not just know how to make a diagnosis but constantly strive to learn something new in order to get ahead of the disease, recognize it in the bud.

Paritpatientiapalmam - "The palm branch is obtained by patience", literally "patience gives birth to the palm branch", that is, by patience and constant work a person can achieve his goal, the palm branch in this case acts as a result, speaking about a medical university or faculty - this is becoming a qualified specialist who is able to recognize the disease and prescribe the correct treatment.

Amatvictoriacuram - "Victory loves diligence." The word "cura, ae $\mathrm{f}$ " in Latin means caring, diligence, effort to do one's business, further curiosity and inquisitiveness, that is, the desire to find out and understand the essence of one's business, then research as a scientific examination or examination to ascertain and establish something or, work as a type of specific activity, care and treatment, veneration and supervision. Thus, the word "cura, ae f" in this aphorism is 
that our mind and our knowledge, no matter how hard we entrust ourselves to them, are so strong as to induce us to act, if, in addition, we do not exercise our soul and accustom it to activity ..." as mental and physical.

\section{IV.DISCUSSION}

A continuation of this expression is a dictum from the collection of maxims Publius Syrah: Bis vincit, qui se vincit in victoria, which translates as "He who triumphs twice, conquers himself as well." Medical education does not consist in obtaining a diploma, a student must go the way of becoming from an inexperienced student to a novice trainee and from a trainee to a confident doctor, but a doctor who is constantly developing, striving for new knowledge and new discoveries, to know himself. Not to be proud, not to lose your personal beginning when you achieve a certain goal - this is the main meaning of this saying.

\section{CONCLUSION}

Thus, relying on Latin winged expressions that help to draw the student's attention to his physical development, the university teacher directs his activities to the formation of the student's personality in general, stimulating the latter to physical education, strengthening his health and enriching with sanitary and hygienic knowledge. "It is difficult to hope

\section{References}

[1] Gilev G.A. Physical education in high school - a means of social protection of students // Mater. Int. scientific - practical conf. Actual problems of maintaining and strengthening the health of youth in the Siberian region. - Irkutsk. 2006, pp. 8-9.

[2] Zhuravleva Yu.S., Kislitsyn Yu.L. Functional state and features of adaptation of first year students from various regions of the world to new climatogeographic and socio-biological environmental factors. M. Technologies of living systems. 2008, vol. 5, 4, pp. 39-45.

[3] Podosinov A.V., Schaveleva N.I. Pliny and his encyclopedia. Lingua Latina. Introduction to the Latin language and ancient culture. Part 2. M.: Progress. 1994, pp. 42.

[4] Michel de Montaigne Experiments. Essays. M.: Eksmo. pp.342.

[5] Kharlamov I.F. Pedagogy. 2nd ed., Erased. Mn.: Higher. School. 2004, 272.

[6] Kislicin Yu.L., Pilipovsky A.Z. Socio-biological foundations of physical education. M. GUU. 2003, pp. 12-13.

[7] Yu.S. Tsybulnik. Winged Latin expressions. Kharkov: Folio; M.: Eksmo. 2007, 992.

[8] Alexsandr S. Kuznetsov. Russian Professor's meeting. Russian Journal of Physical Education and Sport. 2019, 14(1), pp. 17-22. DOI: 10.14526/2070-4798-2019-14-1-18-24 